\title{
REVIEW
}

\section{Mass casualties and triage at a sporting event}

\section{J S Delaney, R Drummond}

Br J Sports Med 2002;36:85-88

When a sports medicine doctor provides coverage for a sporting event with a large number of athletes and spectators, he or she should always be aware that the potential for a large number of injuries exists. In the event of a mass casualty incident that overwhelms the available medical resources, he or she may be the most qualified professional present to triage and organise patient care. Certain basic rules of triage in a disaster situation should be followed, the goal being to save as many lives as possible. Special circumstances, such as crush injuries, lightning strikes, and blast injuries, may affect the triage and initial care of injured patients.

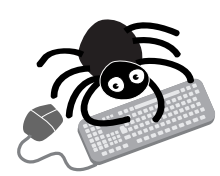

Extra figures to accompany this review can be found on www.bjsportmed.com

See end of article for authors' affiliations

Correspondence to: Dr Delaney, McGill Sport Medicine Clinic, 475 Pine Ave West, Montreal,

Quebec, Canada H2W

1S4; jdelan2@

po-box.mcgill.ca

Accepted

31 October 2001
S ports doctors are often called on to provide medical coverage for sporting events with a large number of athletes and spectators. Usually the doctor is able to deal with each patient one at a time, and most events are completed without major incident. It is possible, however, that he or she may be required to treat a large number of severely injured patients. ${ }^{1}$ Recent events around the globe have again raised our awareness of this possibility. In April 2001, 43 people were killed at a soccer stadium in South Africa, and 126 people were killed in May during a stampede at a soccer match in Ghana. ${ }^{2}$ Unfortunately, these are not isolated incidents, and the number injured may be even greater. In 1992, 17 people were killed and 1900 injured when a temporary grandstand collapsed at a soccer match in Bastia, Corsica. ${ }^{2}$ Mass casualties are not only limited to the world of soccer, and can happen at any sporting event, in any country. At the 1996 Centennial Olympics in Atlanta, Georgia, 111 people were injured when a pipe bomb placed in a knapsack at the Olympic park was detonated. ${ }^{3}$ In Windsor, Ontario, dozens of university football players were knocked to the ground in 1998 after lightning struck a goalpost and travelled along the field (S Cross, personal communication). From a stadium or grandstand collapse to lightning injuries and terrorist bombings, the sports doctor may be the most qualified professional at the scene to initiate and organise care. Knowing a few basic rules of triage and initial patient assessment in a mass casualty or disaster situation may allow the greatest number of lives to be saved.

\section{DISASTERS}

The term disaster has many different connotations. Most people would agree that a major earthquake with thousands injured is a disaster, but a more practical definition is any multiple casualty incident that overwhelms the response capabilities of the available resources. ${ }^{4}$ As such, a handful of patients may overwhelm a single doctor, whereas it may take dozens or hundreds of patients to overwhelm the resources of an event such as the Olympic Games.

In a disaster situation, the doctor's obvious goal is to try to save as many lives as possible. This may involve making difficult decisions as to who will get immediate care and who will not. In some extreme instances, care should actually be withheld from severely injured patients so that limited resources are available for others. For a doctor, withholding care from an injured patient is contrary to what is taught and practised on a day to day basis. In these instances, the doctor needs to remember the extraordinary circumstances with which he or she is faced and keep in mind that difficult decisions must be made to benefit the greatest number of people.

\section{In some extreme instances, care should actually be withheld from severely injured patients so that limited resources are available for others.}

In a disaster, where multiple injuries have occurred, the following priorities remain constant.

\section{(1) Activate the local emergency medical services}

The doctor needs to realise the limitations of his or her own abilities. It is always better to overestimate the severity of a situation than to underestimate it. If an unforeseen incident has overwhelmed the available resources for an event, the doctor should call for help as soon as possible. This will usually mean activating the local emergency medical services. This can usually be accomplished with a single phone call from the scene, but if land phones and the cellular phone system are affected, someone may need to be dispatched by car or foot to alert the authorities. In the meantime, the doctor should triage and care for the injured patients as best as possible.

The doctor should also actively solicit help from others present at the event; there may well be other healthcare professionals there. Even spectators or athletes who have knowledge of basic life support may be invaluable in helping to stabilise and treat patients.

\section{(2) Assess scene safety}

Before beginning triage and care of patients, the doctor should ensure that the surroundings are safe for both caregivers and patients. Although the primary goal is to care for the injured, another 


\begin{tabular}{lll}
\hline Table 1 & \multicolumn{2}{c|}{ Triage colour coding system } \\
\hline Colour & Priority & Description \\
\hline Red & 1 & $\begin{array}{l}\text { May survive if given immediate simple life } \\
\text { saving measures } \\
\text { Should survive if given care within a few } \\
\text { hours }\end{array}$ \\
Yellow & 2 & $\begin{array}{l}\text { Walking wounded: minor injuries that do not } \\
\text { require rapid care } \\
\text { Deceased or severely injured patients unlikely } \\
\text { to survive }\end{array}$ \\
Black & 4 & $\begin{array}{l}\text { Ineen } \\
\text { Injured patients are placed in one of the four colour groups } \\
\text { depending on the severity of their injuries. }\end{array}$ \\
\hline
\end{tabular}

goal is to prevent further injuries. This may involve moving injured patients away from potentially hazardous surroundings, or waiting to enter an area until it has been deemed safe. In the event of a stadium collapse, for example, determining the structural integrity of a structure may be difficult for the doctor and could be better determined by others on the scene who have more experience in this area.

\section{(3) Triage}

The word triage comes from the French word "trier", meaning to sort. Triaging patients was first performed in times of war to decide which soldiers could immediately return to battle after injury and which soldiers could not. ${ }^{5}$ In disaster situations, the goal of triage is to quickly move from patient to patient and rapidly assess and classify the injured in terms of urgency and necessity of care. To this end, triage may involve providing some basic life saving measures, but it is not meant to be the time at which aggressive or definitive care is provided. It should be remembered that triage in a disaster situation is different from triage in a hospital setting in that the time to definitive care is unknown in a disaster situation.

The sports doctor may be the most qualified person to quickly assess and triage the injured patients. It is possible, however, that there may be other healthcare professionals on the scene who are better equipped to triage. These may include paramedics, emergency medical technicians, emergency department nurses, or other doctors. If this is the case, the sports doctor is then able to help provide more definitive and in depth care for the seriously injured patients.

\section{The START system}

Most experts agree that the START (simple triage and rapid treatment) system using the assessment of respirations, perfusion, and mental status is the best strategy. ${ }^{47}$ This system is designed to decide which patients should be transported immediately, which can wait, and which patients are "unsalvageable". Colour coding schemes are commonly used to identify the severity of injury and the category of treatment or evacuation into which the patient should be included (table 1$){ }^{8}$ Although the use of colour patient tags has been described, another practical option is to write the colour code on the forehead of the patient with a marker or pen. Obviously, it is important that all those participating in patient care and evacuation understand and use the same colour scheme.

Initially, all patients who can walk are asked to leave the immediate scene. These patients should be initially coded as green. Next the doctor should move quickly to individual

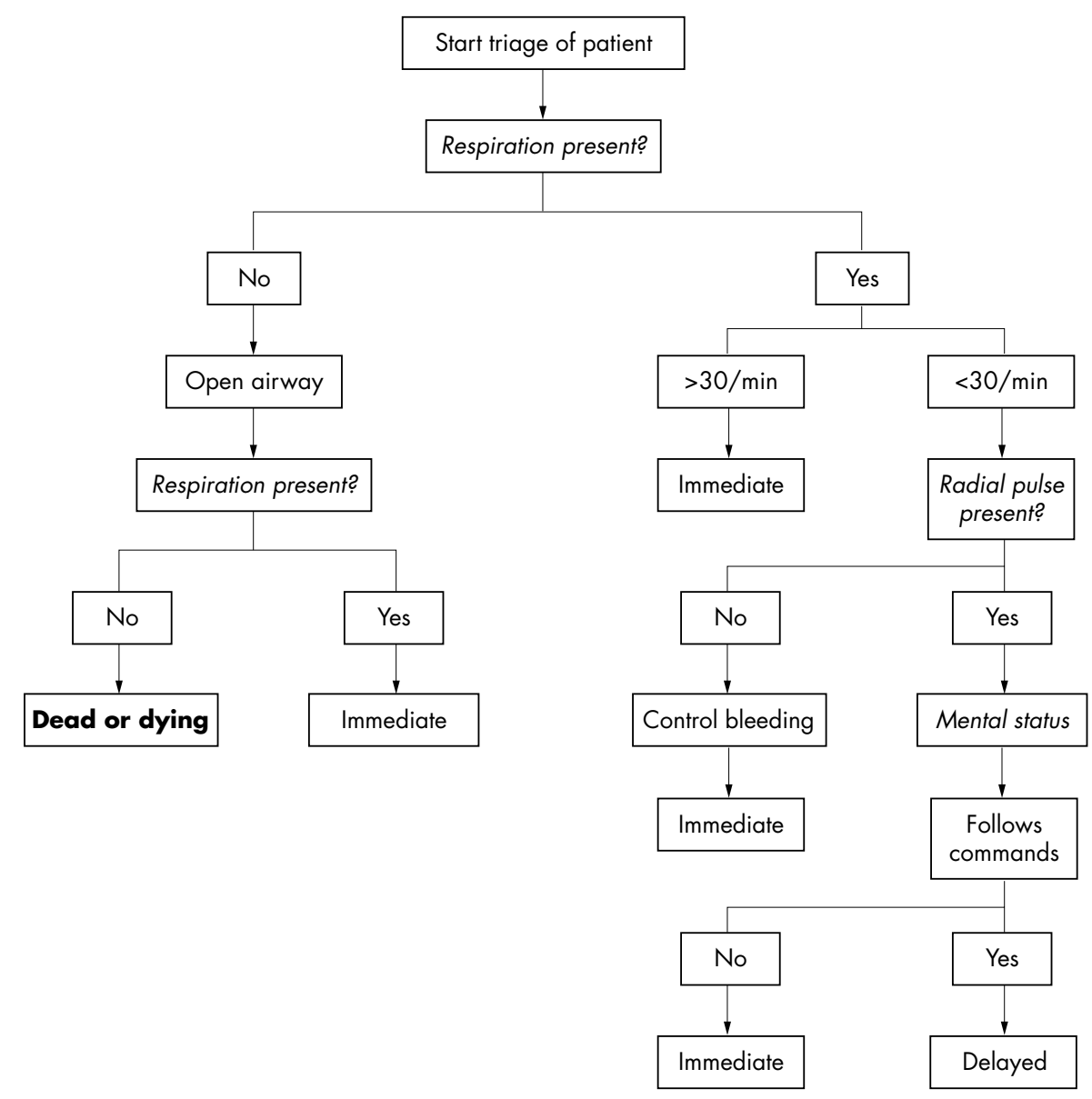

Figure 1 START (simple triage and rapid treatment) system of triage. Patients who must be treated and/or evacuated to hospital are rapidly identified. Adapted from Super et al.? 
patients, assessing respiration, circulation status, and mental status (fig 1). In true disaster situations, cardiopulmonary resuscitation should not be performed during triage. As the doctor moves from patient to patient, the most aggressive measures that should be performed include basic airway opening manoeuvres and application of direct pressure over an obvious external source of bleeding.

Basic airway manoeuvres in a disaster triage situation should be limited to simple procedures such as clearing the airway and performing a chin lift or jaw thrust. The head tilt/ chin lift is recommended by the American Heart Association as the preferred method of opening the airway in the unconscious victim. ${ }^{9}$ One hand is placed on the victim's forehead, and firm pressure is applied to tilt the head backward. The manoeuvre is completed by placing the fingers of the other hand under the bony part of the lower jaw and lifting the chin forward. Although effective in most patients, this manoeuvre should not be performed if there is a possibility that the patient has sustained a cervical spine injury. In many trauma situations, a cervical spine injury should be assumed until proven otherwise. In these situations, the jaw thrust or triple airway manoeuvre should be used. With this technique the head is maintained in a neutral position, and the fingers of both hands are then used to grasp the angle of the mandible, displacing it forward and upward. The mouth is opened by retracting the lower lips and mandible with both thumbs. In line cervical spine immobilisation may be maintained by the doctor or may be performed by an assistant. If a cervical spine fracture is not suspected, the jaw thrust manoeuvre can be made more effective by tilting the head back into slight extension, and is very useful when other manoeuvres have failed to open the airway.

\section{(4) Treat and retriage}

Once an initial triage has been completed, the doctor may then begin more definitive care of patients. Depending on the resources available, this may involve basic life support manoeuvres such as opening and maintaining an airway or compressing an actively bleeding wound. Advanced trauma life support measures, such as performing a needle decompression of a suspected tension pneumothorax, may also be required. The doctor should also remember that it is critical that the patient be reassessed and retriaged. Triage is at best only $70 \%$ correct on initial evaluation and is thus designed to be a dynamic process. ${ }^{5}$ By reassessing patients, the doctor will be able to detect those who may have deteriorated and now may require immediate care.

\section{SPECIAL CIRCUMSTANCES}

Specific situations that may result in multiple casualties at a sporting event may also have unique characteristics that may alter standard triage and care.

\section{Crush injuries}

When patients are caught underneath a collapsed structure, they are at risk of developing crush syndrome. This develops primarily because of the massive rhabdomyolysis that occurs after prolonged pressure on the skeletal muscle. Most crush syndromes result from being under a heavy weight for four hours or more. ${ }^{10}$ The syndrome is complex and may involve hypotension, renal failure, and disseminated intravascular coagulation. The biggest factor in preventing this syndrome is early and aggressive fluid rehydration. Early intravenous access is imperative in any patient that has been trapped underneath a heavy weight for any period of time. From their experience with building collapses, the Israelis have learned that it may take 45-60 minutes from the time of limb exposure to full extrication. ${ }^{11}$ In such circumstances, intravenous access and aggressive hydration is suggested as soon as the limb is

\section{Take home message}

Triage in a mass casualty situation is designed to save as many lives as possible and involves the rapid assessment of respiration, radial pulse, and mental status in an effort to prioritise treatment and evacuation. Basic airway manoeuvres and the application of direct pressure over an obvious source of bleeding are the most aggressive measures that should be performed.

exposed, or as soon as it is feasible. In a patient thought to be otherwise healthy, an initial intravenous drip of normal saline or Ringer's lactate should be started, and a bolus of 500-1000 $\mathrm{ml}$ should be given. Again, the goal is to prevent hypotension and ensure an aggressive diuresis in order to prevent renal failure.

\section{Lightning injuries}

A lightning strike on the field of play or into the stands can result in multiple injuries. These may result directly from the voltage itself, from the trauma of being thrown back from the site of contact, or from extreme muscular contractions of various muscle groups in the body. It is most important to realise that patients injured by lightning can recover fully after being apnoeic and asystolic, if they are supported.

Lightning delivers a large amount of DC current, often more than $1000000 \mathrm{~V}$. This can result in respiratory arrest from an insult to the central nervous system and asystole from the DC current delivered to the cardiac tissue. If the patient's respiratory status can be supported, often the central nervous system will recover and reinitiate respiration. If the circulatory system can be supported with cardiopulmonary resuscitation, the intrinsic electrical activity of the heart may restart organised cardiac contractions. It is often said that triage principles are reversed in the case of lightning injuries, as the patients who appear dead with no respirations and pulse are the ones who are treated aggressively first.

\section{Blast injuries}

In the event of a bombing or explosion, patients can present with a variety of injuries including brain haemorrhage, skull fractures, lung contusions, blunt intra-abdominal visceral damage, and penetration injuries from flying debris. Although not life-threatening itself, many patients near the blast may also have suffered ruptured tympanic membranes. It has been estimated that almost half of all patients seriously injured from bomb blasts have ruptured tympanic membranes. ${ }^{5}$ Patients may be unable to hear because of this injury and may not respond to verbal questioning. This may lead to inappropriate triage and patient disposition if the doctor is not aware of the problem.

\section{CONCLUSION}

Although it is hoped that no doctor will ever have to deal with a scenario in which there are multiple casualties that overwhelm the medical resources available, it has happened in the past and will probably happen again in the future. Owing to the large number of athletes and spectators present at many sporting events, the sports medicine doctor may be forced to deal with such a disaster. Under these difficult conditions, a few simple rules designed to prevent further injury and help deliver the limited resources to the most needy and salvageable patients should be followed. These simple rules may allow the doctor to save many more lives than would otherwise be possible with an unorganised approach to a catastrophic situation. 


\section{ACKNOWLEDGEMENTS}

We thank John Antoniou, Steve Cross, Mary Mooney, and Tracy Troutman Delaney for help with the preparation of this review.

\section{Authors' affiliations}

J S Delaney, Department of Emergency Medicine, McGill University Health Center, Montreal, Quebec, Canada

R Drummond, McGill Sport Medicine Clinic, Montreal

\section{REFERENCES}

1 Leonard RB. Medical support for mass gatherings. Emerg Med Clin North Am 1996;14:383-97.

2 www.sportsillustrated.cnn.com.

3 Feliciano DV, Anderson GV, Jr, Rozycki GS, et al. Management of casualties from the bombing at the centennial olympics. Am J Surg 1998; 176:538-43

4 Schultz CH, Koenig KL, Noji EK. Disaster preparedness and response. In: Rosen P, Barkin RM, eds. Emergency medicine: concepts and clinical practice. St Louis: Mosby Year Book, 1998:324-33.

5 Gans L, Kennedy T. Management of unique clinical entities in disaster medicine. Emerg Med Clin North Am 1996;14:301-26.

6 Schultz $\mathrm{CH}$, Koenig KL, Noji EK. A medical disaster response to reduce immediate mortality after an earthquake. N Engl J Med 1996:334:438-44

7 Super G, Groth S, Hook R. START: simple triage and rapid treatment plan. Newport Beach, CA: Hoag Memorial Presbyterian Hospital, 1994.

8 Kennedy K, Aghababian RV, Gans L, et al. Triage: techniques and applications in decision making. Ann Emerg Med 1996;28:136-44.

9 Dailey RH, Simon B, Young GP, et al. The airway emergency management. St Louis: Mosby Year Book, 1992.

10 Michaelson M. Crush injury and crush syndrome. World J Surg 1992;16:899-903

11 Better OS. Traumatic rhabdomyolysis ("crush syndrome")-updated. Isr J Med Sci 1989;25:69-72.

\section{COMMENTARY}

Mass casualty incidents are emotionally overwhelmingthere is a natural tendency for panic to dominate. In addition, many well meaning volunteers will attempt to help without the expertise necessary to avoid further injury to victims. As the author has stated, healthcare workers hoping to bring aid to victims may place themselves at great risk by entering situations that are dangerous because of either structurally unstable structures or unidentified dangers such as gases, fires, and live electrical wires. It is thus key that the doctor taking charge acts in such a way as to be visibly in charge and under control; this calm will be infectious and allow others who are upset to calm themselves and become a help instead of a hindrance. Ensuring that unnecessary risks are avoided, even if it means waiting for experts to arrive and may mean further death or injury to victims, is a hard decision. It will result in overall greater benefit, although it may not seem so at the time. Equally difficult is the triage decision to pass over a dying patient in order to save more patients.

These are thus the keys to effective management of mass casualties: proper triage, calm leadership, avoidance of further injuries, and making difficult decisions. Let us hope that we do not witness such events too often.

J Ducharme

Department of Emergency Medicine, Saint John Regional Hospital, PO Box 2100 Saint John NB E2L 4L2, Canada; ducji@reg2.health.nb.ca

\section{COMMENTARY}

This review outlines important principles for the management of a situation involving many people with a wide variety of injuries at a sporting event. Sports doctors are not necessarily trained to manage victims of multiple trauma, but a basic understanding of triage principles is important for all doctors who work in a setting where the potential for a disaster exists.

The authors outline basic strategies that may be of practical use for a sports doctor confronted with the undesirable task of sorting through a number of patients with severe and varied injuries. This article is an excellent starting point for those involved in covering sporting events where a large audience can potentially become injured.

R G Marx

Sports Medicine and Shoulder Service, Hospital for Special Surgery, 535 East 70th Street, New York, NY 10021, USA 